\title{
EL PROBLEMA DEL VOTO DE DESCONFIANZA EN LA CONSTITUCION ESPAÑOLA DE 1931 *
}

\author{
POR \\ ANTONIO BAR
}

\begin{abstract}
SUMARIO
I. INTRODUCCIÓN.-II. LA PROBLEMÁtiCa CONSTITUCIONAL DEL VOTO DE DESCONFIANZA: 1. La complementariedad de los artículos 75 y 64 de la Constitución de 1931. 2. La tramitación formal del voto de desconfianza. 3. Consecuencias del voto de desconfianza.-III. Conclusiones.
\end{abstract}

\section{INTRODUCCION}

El régimen político establecido por la II República en España tenía el carácter de parlamentario, y este carácter venía determinado especialmente —además de por otros elementos- por el tipo de relaciones establecidas constitucionalmente entre el Gobierno y las Cortes. La Constitución de 1931, como la mayoría de las constituciones europeas surgidas después de la Primera Guerra Mundial, establecía un tipo de parlamentarismo «racionalizado», en la terminología del por entonces afamado constitucionalista ruso-francés Boris MirkineGuetzévitch ${ }^{1}$. Esta racionalización del sistema parlamentario consistía fundamentalmente en una consagración formal de la supremacía del Parlamento, pero también en el establecimiento de toda una serie de garantías tendentes a conseguir la mayor estabilidad y eficacia posible del Gobierno, que se consagraba como el órgano motor de todo el sistema. Garantías que ahora se especificaban formalmente en la Constitución como principio general —estable-

* Este trabajo fue presentado como una ponencia al II Congreso de la Asociación Española de Ciencia Política, celebrado en Sevilla del 30 de septiembre al 2 de octubre de 1981.

B. Mirkine-Guetzévitch, «Les nouvelles tendances du Droit Constitutionnel», en Revue du Droit Public et de la Science Politique, 45, 1928, págs. 5-53. Este y otros artículos han sido recogidos en versión castellana en Modernas tendencias del Derecbo constitucional, Reus, Madrid, 1934. 
ciendo la necesidad de contar con la confianza del Parlamento para poder gobernar, además de la tradicional responsabilidad política del Gobiernoy mediante la formulación de un procedimiento determinado para la exigencia de la responsabilidad política ministerial.

Así, en el primer sentido, la necesidad de contar con la confianza del Parlamento para poder gobernar fue claramente establecida en Constituciones como la alemana de Weimar de 1919 (art. 54: «El canciller del Reich y los ministros del Reich necesitan de la confianza del Reichstag para ejercer su cargo. Cualquiera de ellos debe dimitir cuando el Reichstag le haya retirado su confianza por acuerdo expreso»), la checa de 1920 (art. 78: «Si la Cámara de Diputados expresa su desconfianza al Gobierno o si rechaza el orden del día en que se contiene un voto de confianza propuesto por él, el Gobierno está obligado a presentar su dimisión al presidente de la República»), la austríaca de 1920 (art. 74: «El Gobierno federal o el ministro al que por una resolución formal el Consejo Nacional le retire su confianza, deberá ser relevado de sus funciones») o la polaca de 1921 (art. 58: «El Consejo de Ministros y cada uno de sus miembros deben dimitir si la Dieta lo exige»). Y, en el segundo sentido, los límites a la exigencia de la responsabilidad ministerial, que por entonces se establecían formalmente por primera vez en los textos constitucionales, fueron de muy diverso tipo y en todos los casos claramente restrictivos de este poder parlamentario. El autor francés Octave Dupond llegó a clasificar hasta cinco principios o técnicas procedimentales destinadas a limitar el poder censurador del Parlamento y que aparecían recogidas en la mayoría de las constituciones de entreguerras. Estas eran ${ }^{2}$ :

1. Sustraer de la libre iniciativa de cada parlamentario la facultad de poner en juego la responsabilidad ministerial, haciendo de esta facultad un derecho colectivo y no individual. Así, Constituciones como la prusiana de 1920, la griega de 1927 o la del Estado de Baviera de 1919 establecían en sus artículos 57,88 y 55 , respectivamente, que toda proposición tendente a destituir al Gobierno o a un ministro debería estar firmada por un número mínimo de diputados.

2. Establecer un espacio mínimo de tiempo entre la presentación o inclusión en el orden del día de la moción de desconfianza y el debate y votación de la misma. Y ello para permitirle al Gobierno el obtener los suficientes apoyos parlamentarios como para poder oponerse a la misma. Este requisito estaba incluido en Constituciones como la austríaca (art. 74), la prusiana (art. 57), la polaca (art. 58) o la griega (art. 88).

3. Someter la proposición de desconfianza al examen de una delegación o comisión de la Cámara antes de que ésta entrase a debatirla y votarla. Así lo establecía la Constitución checa (art. 76), según la cual un comité de la Cámara debía hacer un informe sobre la proposición antes de que ésta la votase.

4. Exigir que la proposición fuese aprobada por una mayoría tal que pudiese considerarse que era una expresión verdadera de los sentimientos de desconfianza de la mayoría de la representación nacional. Así, en gran parte

2 O. Dupond, «La réglementation de la responsabilité ministérielle», en Revue $d u$ Droit Public et de la Science Politique, 51, 1934, págs. 208-220. 
de los casos se exigía que tal proposición fuese votada afirmativamente por la mayoría absoluta de los miembros de la Cámara. Tal ocurrió, por ejemplo, en las Constituciones bávara (art. 55), prusiana (art. 57) y checa (art. 75). Otras Constituciones exigían mayorías diferentes - la griega exigía dos quintos de los diputados (art. 88) - o simplemente un quorum determinado en el momento de la votación, como la Constitución austríaca, que requería la presencia de la mitad de los miembros del Consejo Nacional para la adopción de una decisión en este sentido (art. 74).

5. Impedir que la existencia de un Gobierno pudiese ser puesta en cuestión en intervalos de tiempo demasiado cortos. $\mathrm{Y}$ así, la ya citada Constitución griega de 1927 establecía que una moción de desconfianza no podía ser presentada antes de dos meses a partir de la presentación de otra del mismo género (art. 88).

Así pues, en el establecimiento formal de la necesidad de contar con la confianza parlamentaria para gobernar y en la formulación de un procedimiento específico para exigir la responsabilidad ministerial, radicaba precisamente la gran novedad del constitucionalismo europeo surgido con posterioridad a la Primera Guerra Mundial y de la propia Constitución española de 1931, que, nacida casi al final del período de entreguerras, se vio muy influenciada por el mismo.

Los principios básicos de las relaciones parlamentarias entre el Gobierno y las Cortes venían establecidos en la Constitución de 1931 en los artículos 91, 75 y 64 :

Art. 91: Los miembros del Consejo responden ante el Congreso: solidariamente de la política del Gobierno e individualmente de su propia gestión ministerial.

Art. 75: El presidente de la República nombrará y separará libremente al presidente del Gobierno y, a propuesta de éste, a los ministros. Habrá de separarlos necesariamente en el caso de que las Cortes les negaran de modo explícito su confianza.

Art. 64: El Congreso podrá acordar un voto de censura contra el Gobierno o alguno de sus ministros.

Todo voto de censura deberá ser propuesto, en forma motivada y por escrito, con las firmas de cincuenta diputados en posesión del cargo.

Esta proposición deberá ser comunicada a todos los diputados y no podrá ser discutida ni votada hasta pasados cinco días de su presentación.

No se considerará obligado a dimitir el Gobierno ni el ministro cuando el voto de censura no fuere aprobado por la mayoría absoluta de los diputados que constituyan la Cámara.

Las mismas garantías se observarán respecto a cualquier otra proposición que indirectamente implique un voto de censura.

Sin embargo, la regulación constitucional de estas relaciones era bastante insuficiente - como lo era también en las demás constituciones de la épocay ni siquiera venía complementada por normas de carácter inferior, como lo sería el propio Reglamento interno del Congreso. 
Así, no se regulaba de manera explícita cómo habría de manifestarse la confianza de la Cámara en el Gobierno ni se exigía una presentación formal de cada nuevo Gobierno ante las Cortes para recabar la confianza de las mismas. De esta manera, y a tenor de lo expresamente establecido en la Constitución, parecía como si la confianza de la Cámara se presumiera, salvo que se presentase una moción de censura contra el Gobierno, de acuerdo con los requisitos del artículo 64, u otra proposición que indirectamente la implicase, en cuyo caso, como indicaba el propio artículo 64 en su último párrafo, se habrían de observar las mismas garantías que para el voto de censura.

De hecho, esta misma situación era la que se producía en Alemania según la Constitución de Weimar, en cuyo artículo 54 se inspiraba el artículo 75 de la Constitución española de 1931. Allí, al no exigirse que la confianza se manifestase mediante un acuerdo expreso - al contrario que la censura o desconfianza, según el citado art. 54-, el Gobierno, una vez designado y en posesión del cargo, se consideraba que gozaba de la confianza del Reichstag mientras éste no se la retirase de manera expresa ${ }^{3}$.

Por otra parte, el poder del presidente de la República de nombrar y separar libremente al presidente del Gobierno y a sus ministros a propuesta de éste último (art. 75) -poder que sólo contaba con la limitación de tener que separarlos obligatoriamente en el caso de que las Cortes les negaran de modo explícito su confianza-, no viene sino a ratificar la idea de que la confianza parlamentaria podía presumirse por parte del Gobierno siempre que no mediase la retirada expresa de la misma. Además, la confianza del presidente de la República adquiría así un carácter predominante sobre la del Congreso, pues mientras que este último había de recurrir a un procedimiento muy restringido para retirársela al Gobierno (art. 64), formalmente el presidente de la República no contaba con esta limitación, pudiendo nombrarlo y separarlo libremente. De hecho, en la terminología política de la época se solía hablar del «voto de confianza» del presidente de la República o de plantear la «cuestión de confianza» al mismo - significándose con ello el acto del presidente del Gobierno ante un evento determinado de inquirir al presidente de la República si aún contaba con la confianza que éste le había otorgado en el momento de su designación y de ponerse a su disposición a todos los efectos-, empleando un significativo paralelismo con lo que habría de ser un necesario voto de confianza de la Cámara, no regulado constitucionalmente y al que se equiparaba la confianza presidencial, en el sostenimiento del Gobierno ${ }^{4}$.

Sin embargo, la práctica constitucional determinó que los Gobiernos acudiesen en la mayoría de los casos a recabar la confianza de las Cortes al inicio de su mandato. Aunque, desde luego, no todos lo hicieron - por muy diversos motivos- ni los que lo hicieron lo hicieron siempre al comienzo de su man-

${ }^{3}$ O. Bühler, La Constitución alemana de 11 de agosto de 1919, Labor, Madrid, 1931, página 78

${ }^{4} \mathrm{E} 1$ poder presidencial, que incluía la libre disolución del Congreso (art. 81), y la doble responsabilidad del Gobierno, ante el presidente de la República y el Parlamento, hacían del régimen constitucional español de 1931 un sistema parlamentario que tenía más de dual que de monista. Sobre la distinción entre regímenes duales y monistas, véase L. Duguit, Traité de Droit Constitutionnel, II, Fontemoing, París, 1928. 
dato. La confianza de la Cámara se expresaba entonces a través de la aprobación de una proposición incidental presentada en medio del debate sobre la declaración ministerial inicial por un grupo de diputados formantes generalmente de las minorías que constituían el Gobierno. Por otra parte, y a pesar de haber acudido el nuevo Gobierno formalmente a las Cortes con una declaración ministerial, no siempre llegó a presentarse esta proposición de confianza. De hecho, si analizamos cada uno de los casos de los veinte Gobiernos que tuvo la II República hasta el comienzo de la guerra civil, vemos que dos de ellos se presentaron formalmente a las Cortes y recibieron su confianza por «asentimiento» ${ }^{5}$ o aclamación, es decir, sin que se llegase a realizar la votación de una proposición de confianza; nueve se presentaron formalmente y su declaración ministerial fue seguida de la votación favorable de una proposición de confianza; uno se presentó también formalmente, pero su declaración ministerial fue seguida de la aprobación de una proposición de desconfianza que le obligó a dimitir; dos no llegaron a presentarse formalmente por haber sido disueltas las Cortes; cinco no se presentaron de una manera formal ni, por tanto, se llegó a votar proposición de confianza alguna, y, finalmente, uno no se presentó formalmente, pero se aprobó una proposición que implicaba indirectamente el darle la confianza de la Cámara.

Esta falta de determinación legal, esta carencia de una regulación precisa, en toda su amplitud, de las relaciones de confianza entre el Gobierno y las Cortes no podía dejar de crear conflictos, sobre todo en los primeros meses de vida del nuevo régimen constitucional, cuando aún la práctica no había determinado siquiera la existencia de una cierta normativa consuetudinaria.

Y, efectivamente, el problema se planteó el 2 de octubre de 1933, cuando el primer Gobierno Lerroux, que había sido nombrado el 12 de septiembre de 1933, tras la dimisión del anterior Gobierno Azaña, acudió a las Cortes presentándose formalmente con una declaración ministerial. Entonces, ante la falta de presentación de una proposición de confianza por parte de la minoría gubernamental —como era lo más frecuente-, la minoría socialista, en aquel momento ya en la oposición, presentó una proposición en la que se decía textualmente:

«A las Cortes Constituyentes.-Los diputados que suscriben, después de oír las manifestaciones del señor presidente del Consejo de Ministros, ruegan a las Cortes que sirvan declarar que el Gobierno nombrado el 12 del mes de septiembre último y que hoy se presenta al Parlamento no merece su confianza» ${ }^{6}$.

La proposición socialista, que iba firmada en primer lugar por Indalecio Prieto, implicaba un voto de desconfianza para el Gobierno Lerroux y suponía una verdadera novedad en la práctica seguida hasta entonces en las relaciones

\footnotetext{
${ }^{5}$ Cfr. artículos 53 y 82 de los Reglamentos provisional y definitivo, respectivamente, de las Cortes republicanas.

- Diario de Sesiones de las Cortes Constituyentes, 404, 2 de octubre de 1933, página 15399.
} 
entre el Gobierno y las Cortes. Sin embargo, después de un largo debate que llegó a durar dos días, la proposición citada fue puesta a votación por el presidente de la Cámara y sería aprobada por 187 votos contra 91, lo que supuso la manifestación de la desconfianza de la Cámara en el Gobierno, y éste tuvo que ser relevado por el presidente de la República, Alcalá-Zamora ${ }^{7}$.

\section{LA PROBLEMATICA CONSTITUCIONAL DEL VOTO DE DESCONFIANZA}

La justificación jurídica a la que se atuvo la minoría socialista, por boca de su portavoz y primer firmante de la proposición Indalecio Prieto, fue el artículo 75 de la Constitución, el cual, como ya hemos visto, exigía en su último apartado la «separación» del Gobierno por parte del presidente de la República en el caso de que las Cortes le negasen de modo explícito su confianza. «Si a su señoría hoy las Cortes Constituyentes le niegan la confianza - dijo entonces Prieto a Lerroux-, automáticamente el señor presidente de la República, en cumplimiento del artículo 75 de la Constitución, tiene que separar a su señoría y a los demás ministros de los cargos para que fueron nombrados por decretos que el señor presidente firmó» ${ }^{8}$.

Así, considerado el artículo 75 de una manera aislada y no existiendo otros requisitos exigidos por el mismo o por el Reglamento de la Cámara para este tipo de actos, la proposición de desconfianza no requiriría más que una mera votación y su aprobación por mayoría simple. Y de esta manera lo estimó el propio presidente del Congreso, el también socialista Julián Besteiro, quien dio trámite a la proposición como si de algo similar a las habituales proposiciones de confianza, que se solían presentar tras las declaraciones iniciales de los nuevos Gobiernos, se tratase. Para Besteiro, la proposión de la minoría socialista no era una moción de censura y, por ello, no necesitaba reunir los requisitos exigidos para ésta por el artículo 64 de la Constitución. «... En ningún momento la proposición presentada ayer ha sido considerada por mí como un voto de censura - dijo entonces Besteiro-. A mi modo de ver, no podía serlo, puesto que no había actuación de Gobierno. Si yo la hubiera considerado de censura no la hubiera dado la tramitación que ha tenido» ${ }^{9}$.

Por el contrario, Alejandro Lerroux, como presidente del Gobierno puesto en cuestión, estimó que la proposición socialista era semejante a un voto de censura y que, por tanto, había de ser tramitada de acuerdo con los requisitos del artículo 64 de la Constitución. «Su señoría — dijo dirigiéndose a Prietoha presentado un voto de desconfianza que está incluido en los preceptos de la Constitución como semejante a un voto de censura y que debe, por tanto, ser tramitado como tal» ${ }^{10}$.

Así pues, en este conflictivo asunto se encerraba un triple problema que

7 DSCC, 405, 3 de octubre de 1933, pág. 15442.

8 Ibíd., pág. 15433.

Ibíd., pág. 15434.

${ }^{10}$ Ibíd., pág. 15434. 
afectaba de lleno a la interpretación del contenido de la propia Constitución y a su aplicación.

1. Por una parte, se planteaba el problema de si se podía considerar al artículo 75 - sobre todo en lo que a su último apartado se refiere- como un precepto independiente, del cual se podía derivar una consecuencia práctica inmediata, tal cual era la proposición de desconfianza socialista, o si, por el contrario, se debía considerar a este precepto como un principio de carácter dogmático cuya concréción o desarrollo no era otro que el propio artículo 64, que regulaba la moción o voto de censura.

2. Y, en segundo lugar, aun en el supuesto de que se admitiese el que el artículo 75 era un precepto independiente y completo, del que se podían derivar consecuencias prácticas inmediatas, se planteaba el problema de si la tramitación de la desconfianza en él prevista había de atenerse a las normas simples que regulaban las proposiciones de voto de confianza o si, por el contrario, dadas las especiales consecuencias de un voto de desconfianza, la proposición en este sentido debía regularse por las normas establecidas en el artículo 64 para la moción de censura, tal y como el párrafo final del propio artículo decía, por ser las consecuencias de la aprobación de ambos votos prácticamente iguales: la destitución del Gobierno.

3. Pero, en tercer lugar, tal y como se plantearon los hechos, cabría hablar también de la reglamentariedad de la votación realizada teniendo en cuenta que el Gobierno Lerroux presentó su dimisión antes de que finalizase el debate y que, por tanto, se estaba votando sobre la negación de confianza a un Gobierno ya prácticamente inexistente. $Y$, finalmente, íntimamente unido con esto, aún habría que analizar la pertinencia de las consecuencias que de la aprobación del voto de desconfianza la minoría socialista pretendía derivar, cual era la inhabilitación de los miembros del Gobierno Lerroux para formar un nuevo Gabinete.

\section{La complementariedad de los artículos 75 y 64 de la Constitución de 1931}

En lo que se refiere al primer aspecto de la problemática planteada, cabe decir que, para la práctica generalidad de la doctrina y de los comentaristas constitucionales de la época, los artículos 64 y 75 de la Constitución de 1931 eran absolutamente complementarios. En este sentido se manifestaron autores nacionales como Posada, Pérez Serrano, Royo Villanova, Sabino Alvarez Gendín, etc., para quienes el artículo 75 establecía el principio general de la necesidad de contar con la confianza de las Cortes para poder gobernar, mientras que el artículo 64 formulaba los mecanismos concretos a través de los cuales esta confianza podía ser denegada.

En su conocido trabajo sobre la Constitución española de 1931, Adolfo Posada estimaba que, frente a la tradición constitucional anterior, en la que la armonía en las relaciones de confianza entre el Gobierno y el Parlamento se conseguía sin la existencia de una regla fija establecida de manera constitucional con anterioridad, la Constitución de 1931, para evitar las corruptelas a que 
este sistema había llevado, había seguido el principio normativo, según el cual, mediante mandato constitucional, el Gobierno debía contar con la confianza del Parlamento y se condicionaba la forma, las reglas y los efectos del voto de censura como manera de retirarla ${ }^{11}$. Así pues, ambos artículos 75 y 64 eran en su perspectiva absolutamente complementarios, y más explícitamente llegó a decirlo aún en otra ocasión, cuando, caracterizando a la nueva Constitución española, destacaba que el hecho de que ésta «subordinase el funcionamiento ministerial a la necesidad de contar con la confianza de las Cortes» venía establecido en el artículo 75, «en relación con el 64» ${ }^{12}$.

En similar sentido se manifestó Nicolás Pérez Serrano cuando, en su comentario sistemático a la Constitución de 1931, al referirse al artículo 75 resaltaba que el único límite que tenía el presidente de la República en su poder de nombrar y destituir al Gobierno era precisamente la obligación que tenía de «separarlo» cuando éste hubiera perdido la confianza de la Cámara por haber recibido «un voto explícito de censura» ${ }^{13}$. Lo que significa que, en su perspectiva, ésta y no otra era la única forma en la que tal confianza podía ser retirada, es decir, mediante la activación del artículo 64. Dicho en otras palabras: para él, la característica parlamentaria del nuevo régimen republicano consistía precisamente en que «los ministros han de acudir a la Cámara cuando ésta lo exija y pueden ser destituidos por ella mediante el voto de censura» ${ }^{14}$.

Para Antonio Royo Villanova, la relación existente entre los artículos 75 y 64 -para él contradictoria- era precisamente una de las notas criticables de las muchas que encontraba en la Constitución de 1931, con la que estaba en gran parte en desacuerdo. Para él, el principio general y amplio de la responsabilidad gubernamental o de la necesidad de contar con la confianza parlamentaria para gobernar, establecido en los artículos 91 y 75, venía contradicho por el artículo 64, que suponía la introducción de «trabas y limitaciones a la soberanía política del Parlamento» ${ }^{15}$. Pero en cualquier caso, y aun desde un punto de vista crítico, estaba también muy clara para este autor la íntima relación existente entre ambos artículos.

En un sentido justamente contrario al de Royo Villanova, el administrativista Sabino Alvarez Gendín sostenía no sólo que los artículos 64 y 75 eran complementarios, sino que si «los constituyentes hubieran alterado la ordenación de los artículos, colocando el precepto del 64 a continuación del texto del 75, nadie apreciaría la contradicción. Todos nos hubiéramos apercibido de que el 64 detallaba, desmenuzaba, regulaba el principio consagrado en todo régimen parlamentario relativo a la confianza que el Gobierno ha de gozar de

"A. Posada, La nouvelle Constitution espagnole: Le régime constitutionnel en Espagne, Recueil Sirey, París, 1932, págs. 197-200.

${ }_{12}$ A. Posada, «Ảlgunas reflexiones sobre la nueva Constitución española», en Revista de Derecbo Público, I, 5, mayo 1932, págs. 129-135.

${ }_{13}$ N. Pérez Serrano, «La Constitución española de 1931», en Revista de Derecho Privado, Madrid, 1932, pág. 256.

${ }_{14}$ N. Pérez Serrano, "Carácter de la nueva Constitución española», en Revista de Derecho Público, I, 1, enero 1932, págs. 9-16.

${ }_{15}$ A. Royo Villanova, La Constitución española de 9 de diciembre de 1931, Imprenta Castellana, Valladolid, 1934, pág. 194. 
las Cortes» ${ }^{16}$. Y en su apoyo citaba a autores como García Oviedo ${ }^{17}$, que, en realidad, no venían sino a reiterar lo ya expuesto.

En fin, continuar la lista de autores y citas alargaría innecesariamente este trabajo. Baste, finalmente, citar a quien, sin ser un afamado constitucionalista de la época, sí se convirtió, por su especial protagonismo en los hechos que sirven de base a este estudio, en un comentarista de imprescindible referencia. Me refiero al propio presidente de la República, Alcalá-Zamora, quien en su libro crítico sobre la Constitución de 1931 se refirió de manera específica a las relaciones entre los artículos 64 y 75 . Para Alcalá-Zamora, como para los anteriores autores, ambos artículos eran complementarios, pero su complementariedad tenía un sentido diferente, pues, en vez de ser el artículo 64 el desarrollo normativo del principio general contenido en el artículo 75 , en su opinión era este último artículo el que venía a completar a los preceptos contenidos en el artículo 64. «Al redactarse el artículo 75 -dijo Alcalá-Zamora-, precisamente como reconocimiento de prerrogativas presidenciales, no pudo pensar ni creyó nadie que este otro desvirtuara al 64, permitiera eludir la observancia y garantías del mismo y se refiriese a supuestos distintos para burlar aquel otro. La armonía entre ambos preceptos es clarísima. Observándose los requisitos del artículo 64, un voto de censura debe obligar a los ministros a dimitir, pero si ellos fueren remisos, indelicados, morosos en el cumplimiento de su deber, entonces, y sólo entonces, el presidente de la República se ve obligado a separarlos, cumpliendo un deber para hacer cumplir al Gobierno el que olvidó. El artículo 75 es tan sólo el refuerzo del 64 y casi una mera amenaza para que ministros obstinados no abusen de la necesidad del refrendo resistiendo el voto de censura y negándose a dimitir» ${ }^{18}$. La tesis de Alcalá-Zamora, siendo bastante insólita, no me parece, desde luego, demasiado acertada. Sin embargo, no deja de ser significativa, porque, aun desde una perspectiva diferente y con el valor de ser la visión de un protagonista destacado, insiste en el tema que me parece central en el problema que estamos estudiando: la inseparable relación existente entre los artículos 64 y 75 de la Constitución de 1931.

Pero si acudimos a la mens legislatoris, a la verdadera intención del constituyente, nos encontramos con un panorama muy parecido. Los artículos a los que nos referimos son quizá de los menos discutidos y pasan prácticamente intocados del propio proyecto de la Comisión Jurídica Asesora, nombrada por el Gobierno provisional, al texto definitivo de la Constitución. Así, las Cortes Constituyentes ni en la Comisión redactora ni en la discusión plenaria introdujeron grandes modificaciones sobre lo que la Comisión Jurídica Asesora había dicho acerca de la responsabilidad ministerial o de las relaciones de confianza Gobierno-Cortes. De esta manera, si, por una parte, la práctica ausencia de debate sobre estos temas nos impide profundizar en las diferentes perspectivas sobre los mismos, por otra, el hecho de que se mantuviese prácticamente la

${ }^{16} \mathrm{~S}$. Alvarez Gendín, «El voto de desconfianza en la Constitución española», en Revista General de Legislación y Jurisprudencia, 163, 1, julio 1933, págs. 687-691.

${ }_{17}$ García Oviedo, «La nuova Costituzione espagnola», en Rivista di Diritto Pubblico, 1932, pág. 186.

${ }_{18}$ N. Alcalá Zamora, Los defectos de la Constitución de 1931, Imprenta R. Espinosa, Madrid, 1936, pág. 138. Existe una reedición reciente, Civitas, Madrid, 1981. 
misma redacción inicial en ambos artículos deja bien a las claras cuál era la voluntad del constituyente.

El principio de que el Gobierno necesitaba de la confianza parlamentaria para poder gobernar, establecido en el último párrafo del artículo 75, así como el de la responsabilidad política, establecido en el artículo 91, pasaron inalterados del proyecto de la Comisión Jurídica Asesora al texto definitivo de la Constitución. Sin embargo, el artículo 64 sería modificado en su párrafo primero, introduciéndose por la Comisión constitucional de las Cortes la responsabilidad política individual de los ministros por su propia gestión ministerial, y, lo que es más importante a nuestros efectos, también sería modificado en su párrafo último.

Así, la modificación más importante realizada en este terreno fue la que suprimió del último párrafo del artículo 50 (63 de la Comisión y 64 de la Constitución) del texto de la Comisión Jurídica Asesora la alusión explícita que éste hacía al voto de confianza, el cual exigía para su aplicación los mismos requisitos que para la propia censura. Decía este párrafo:

«Las mismas garantías se observarán para el voto de confianza o cualquiera otra proposición que implique indirectamente un voto de censura» ${ }^{19}$.

Esta es la manifestación más obvia de la íntima relación que el constituyente quiso establecer entre los artículos 64 y 75 de la Constitución de 1931. Pero, quizá por ser demasiado obvia y quizá porque, por un indudable defecto de redacción, la Comisión Jurídica Asesora decía «confianza» donde debería haber dicho «desconfianza»-dado que nada tiene que ver confianza y censura, y sería poco lógico exigir los mismos requisitos para un voto de confianza que para un voto de censura cuando de lo que se trataba era de asegurar la estabilidad del Gobierno-; la Comisión de las Cortes decidió suprimir esa alusión expresa a la confianza - -en realidad, desconfianza-, con lo que la relación íntima entre el artículo 75, como principio general, dogmático, y el artículo 64, como norma de desarrollo y aplicación del anterior, pasó de ser explícita a implícita, creándose así la base para su errónea interpretación.

Pero, es más, la imposibilidad de que el artículo 75 pudiese ser interpretado como un precepto independiente, del cual podía derivarse la posibilidad de una proposición de desconfianza para derribar al Gobierno, viene determinada también por la no modificación del mismo en el sentido que proponía el voto particular que Adolfo González Posada presentó al anteproyecto de la Comisión Jurídica Asesora. En él, con buen criterio y adelantándose a las formulaciones del constitucionalismo posterior, proponía que el artículo 60 del anteproyecto -que luego pasaría a ser el 75 de la Constitución- estableciese de manera específica que el Gobierno debía formarse «de modo que represente el sentir de la mayoría del Congreso de los Diputados» ${ }^{20}$, es decir,

19 Anteproyecto de Constitución de la República española que eleva al Gobierno la Comisión Jurídica Asesora, Madrid, 1931, pág. 42.

${ }^{20}$ Anteproyecto de Constitución..., cit., pág. 125. 
exigiese un voto de investidura. De esta manera, si el Gobierno no pudiese llegar a ser constituido por no obtener la confianza de la Cámara y la situación se mantuviese así por más de dos meses, el presidente de la República tendría que disolver el Congreso. La aprobación de esta modificación del artículo 75 hubiese dado sentido y justificación legal a una proposición como la presentada por la minoría socialista. Sin embargo, su no aprobación y el hecho de que el artículo pasase prácticamente inalterado al texto de la Constitución son también una buena prueba de la voluntad del constituyente, que prefirió presumir la confianza de las Cortes y hacer que ésta sólo pudiese ser retirada a través del voto de censura.

Por otra parte, y también ratificando esta tesis, el Derecho constitucional comparado de la época, en algunas de cuyas constituciones se había inspirado la española de 1931, nos ofrece indudables muestras de cómo el principio de la responsabilidad política gubernamental y su exigencia por parte del Parlamento va unido a unos mecanismos formales explícitos que, como ya vimos en un principio, tendían a racionalizar el control parlamentario y asegurar la estabilidad de los Gobiernos. Y así, en la mayoría de las constituciones de entreguerras, al mismo tiempo que se establecía formalmente el principio de la necesidad de la confianza del Parlamento para poder gobernar y el principio de la responsabilidad política.ministerial, se aludía también a los mecanismos concretos a través de los cuales la primera se habría de mostrar y sobre todo la segunda se habría de exigir. Tal es el caso, como ya vimos también anteriormente, de las Constituciones bávara (14-VIII-1919), checa (25-II-1920), austríaca (1-X-1920), prusiana (30-XI-1920), polaca (17-III-1921) o griega (2-VI-1927).

Así pues, parece claro que los artículos 64 y 75 no eran sino las dos partes de una misma cosa, por lo que, a tenor de lo dicho, no era demasiado acertado, jurídicamente hablando, el desvincularlos, como lo hizo la minoría socialista en octubre de 1933 para derribar al Gobierno Lerroux, tratando de derivar consecuencias diferentes de ambos artículos. $Y$ en cualquier caso - como veremos a continuación-, aunque ello fuera así y —como dijo Prieto en aquel entonces- la desconfianza fuese algo totalmente diferente a la censura, la consecuencia lógica de ambas - derribar al Gobierno- exigía una tramitación determinada igual a la del voto de censura regulado en el artículo 64 y a tenor de lo dicho en el último párrafo del mismo.

\section{La tramitación formal del voto de desconfianza}

Suponiendo que el artículo 75 de la Constitución de 1931 fuese un precepto independiente del cual pudiese derivarse la posibilidad de la existencia del voto de desconfianza contra el Gobierno como una figura específica, el segundo aspecto del problema que planteó la proposición incidental socialista fue el de cuál habría de ser la vía adecuada para su tramitación.

Para el presidente del Gobierno puesto en cuestión, Alejandro Lerroux, la proposición de la minoría socialista debería atenerse a los requisitos exigidos por el artículo 64 para el voto de censura y proposiciones similares: «Su señoría 
- dijo éste a Prieto- ha presentado un voto de desconfianza que está incluido en los preceptos de la Constitución como semejante a un voto de censura y que debe, por tanto, ser tramitado como tal» ${ }^{21}$. Y precisamente por no atenerse a tales requisitos, entendía que la proposición debía ser rechazada.

Por el contrario, el portavoz socialista, Indalecio Prieto, sostuvo que la desconfianza era algo totalmente diferente de la censura y que, por tanto, no tenía por qué someterse a los trámites que específicamente para esta figura establecía el artículo 64 de la Constitución. «El señor Lerroux - dijo Prietoha confundido el voto de censura con el de desconfianza. Yo no he presentado una proposición que entrañe un voto de censura, sino una proposición que niega la confianza al Gobierno (...). Gramaticalmente, señor Lerroux, confianza es esperanza firme y se refiere al porvenir; censura es la tacha de un pasado. Son dos cosas completamente distintas. Las distingue la gramática, las distingue el sentido común y, en último término, en caso de duda debía distinguirlas clara, nítida y diáfanamente la nobleza de su señoría y la historia parlamentaria de su señoría» ${ }^{22}$. Para él, pues, la desconfianza debería seguir los mismos trámites sencillos que se utilizaban para la aprobación de los votos de confianza que se solían proponer en los debates sobre las declaraciones ministeriales iniciales o con motivo de determinadas actuaciones gubernamentales.

Desde mi punto de vista, la argumentación de Prieto en el debate, aunque brillante e ingeniosa, era jurídicamente endeble, y sorprende que no hubiese tenido una contestación más contundente en este terreno por parte del Gobierno, que se limitó a ocuparse de otros aspectos menos técnicos de la discusión. En el fondo, el propio Lerroux no alcanzaba a comprender la complejidad técnica del problema ( «Yo no estoy dispuesto a esperar aquí el voto de las Cortes relacionado con un asunto que yo no puedo discutir suficientemente» ${ }^{23}$, llegó a decir), y de aquí que el debate derivase por terrenos más personales y puramente fácticos.

Como ya vimos anteriormente, una de las ideas fundamentales que inspiraban al parlamentarismo «racionalizado» que se extendió por Europa al final de la Primera Guerra Mundial era precisamente el asegurar la estabilidad de los Gobiernos, que habían llegado a convertirse -en casos como Francia, por ejemplo- en meras marionetas de la asambleas en la medida en que el poder del Parlamento se había ido ampliando a costa del de la Corona, dejando al Gobierno un tanto desprotegido en el medio de ambos. Y para conseguir esto, las nuevas constituciones introdujeron en sus textos mecanismos específicos de control de la actividad gubernamental -antes inexistentes en los textos constitucionales, dado que las relaciones Gobierno-Parlamento se venían regulando por lo que Dicey denominó convenciones constitucionales ${ }^{24} \mathrm{o}$ por los reglamentos internos de las Cámaras- que establecían unos cauces y unos límites formales a la exigencia de la responsabilidad política ministerial por parte del Parlamento. En este sentido, para las constituciones de la época,

${ }^{21}$ DSCC, 405, 3 de octubre de 1933, pág. 15434.

22 Ibid., pág. 15434.

${ }^{23}$ Ibid., pág. 15434.

${ }^{24}$ Cfr. A. V. Dicey, Introduction a l'étude du Droit Constitutionnel, Giard et Brière, Paris, 1902. 
desconfianza y censura eran prácticamente sinónimos ${ }^{25}$, y constitucionalistas tan destacados e influyentes entonces como el ya citado Boris Mirkine-Guetzévitch o, entre nosotros, el propio Pérez Serrano empleaban ambos términos indistintamente ${ }^{26}$. La confianza de las Cámaras en la mayoría de los casos se presumía y los Gobiernos no tenían que acudir necesariamente a lo que hoy se denomina voto de investidura. En este sentido, un Gobierno sólo habría de retirarse cuando hubiese recibido un voto de censura -0 de desconfianzao cuando hubiese perdido un voto de confianza. En este último aspecto cabe decir que las proposiciones o votos de confianza eran más una ratificación de la confianza que se presumía que una puesta en cuestión de la misma, dado que sólo eran propuestas por la minoría gubernamental y con esa intención exclusiva. Si cupiese la menor duda de que un voto de confianza no iba a ser aprobado, ni el Gobierno ni su minoría parlamentaria llegarían a proponerlo. Por ello, cuando se hablaba de desconfianza se hablaba más en el sentido de voto de censura que en el sentido de pérdida de un voto de confianza, y de aquí que por aquel entonces censura y desconfianza se convirtiesen en términos sinónimos desde el punto de vista de la práctica parlamentaria.

La Constitución española de 1931 no fue una excepción en esta corriente, como lo demuestra la existencia del artículo 64 , el cual no sólo establecía unos requisitos restrictivos determinados para la moción de censura, sino también - como rezaba el último párrafo del citado artículo- para «cualquier otra proposición que indirectamente implique un voto de censura».

En este sentido no cabe ninguna duda de que el pretendido voto de desconfianza que defendió Indalecio Prieto era una verdadera moción de censura «indirecta», pues de lo que se trataba - como con el voto de censura- era de derribar al Gobierno. Y precisamente para evitar el fácil derribo de los Gobiernos se había establecido el citado artículo, con sus cauces restrictivos.

Pero además, y aun siguiendo la argumentación de Prieto, el carácter de ser algo referido al «porvenir» y no a algo que ya tenía vigencia en el pasado, que él atribuía a la desconfranza para distinguirla de la censura, y en base al cual justificaba la presentación de su proposición frente al Gobierno como si se tratase de algo nuevo, carecía en cierto modo de valor, pues el Gobierno Lerroux había sido nombrado casi un mes antes del debate en el que se presentó la proposición $\mathrm{y}$, por tanto, había realizado ya un buen número de actos, suficientes como para que no se le pudiese considerar inestrenado.

La distinción radical, en fin, que hacía Prieto entre la desconfianza y la censura era algo más que dudosa, y el argumento semántico utilizado ignoraba el aspecto técnico-jurídico del problema, decisivo en la cuestión que se estaba tratando. Como dijo por aquel entonces Alvarez Gendín, «el voto de desconfranza implica un voto de censura de la Cámara a toda política desarrollada por el Gobierno o a aquella que, sin baberla desarrollado éste, sino simple. mente iniciado, se baya becbo ostensible su propósito de proseguirla en una declaración ministerial»» ${ }^{27}$. Es decir, que al ser la moción de censura o sus cauces

${ }^{25}$ Cfr. Constituciones y artículos ya citados anteriormente en este trabajo.

${ }^{26}$ B. Mirkine-Guetzévitch, op. cit.; N. Pérez Serrano, Tratado de Derecho politico, Civitas, Madrid, 1976, pág. 825 .

z' S. Alvarez Gendín, op. cit. E1 subrayado es mío. 
la única forma prevista constitucionalmente entonces para retirarle la confianza al Gobierno, nada impedía que ésta pudiera ser interpuesta contra una declaración inicial de un Gobierno recién formado, por lo que esta es la vía que debía haber utilizado la minoría socialista para derribar al Gobierno Lerroux. Claro que de lo que se trataba precisamente era de huir de los restrictivos requisitos que imponía el artículo 64 de la Constitución, y por ello se utilizó el subterfugio del voto de desconfianza, basándose en el último párrafo del artículo 75 . Pero ello, ante la inexistencia constitucional del voto de investidura, suponía ir contra la lógica interna de la Constitución y dar un trato desigual al Gobierno recién formado con respecto al que ya lleva bastante tiempo actuando. Como diría dolido Alcalá-Zamora años más tarde, «para ellos, el voto de censura se le opone a un Gobierno que ya ha gobernado y exige todos los requisitos, mientras que el de desconfianza repele, sin recibirlo, por simple prejuicio de hostilidad, al Gobierno que se constituye y no está sometido tal voto ni a anuncio, ni a plazo, ni a mayoría. Es absurdo suponer que un Gobierno que al ejecutar actos ha podido incurrir en culpas, incluso muy graves, sea de mejor condición que el que llega con la inocencia del nacimiento» ${ }^{28}$. Aunque, claro está, esta argumentación tampoco tendría validez si, como digo, la propia Constitución hubiese establecido el voto de investidura.

Así pues, a mi modo de ver, el presidente de las Cortes, Besteiro, no debió haber aceptado a trámite la proposición de la minoría socialista, dado que implicaba una censura indirecta y, sin embargo, no reunía los requisitos exigidos por el último párrafo del artículo 64 para tal tipo de proposición ${ }^{29}$.

\section{Consecuencias del voto de descontianza}

Una de las consecuencias más inmediatas que se derivaron del debate sobre el voto de desconfianza propuesto por la minoría socialista de las Cortes Constituyentes fue la dimisión del primer Gobierno Lerroux, que pretendió con esto evitar la votación de la proposición, en la que era seguro que iba a ser derrotado, ante la falta de apoyo de la mayoría de los grupos parlamentarios, incluso de aquellos de los cuales había obtenido ministros. Sin embargo, a pesar de haber manifestado su voluntad de dimitir y de haber pedido el final del debate para poder acudir a presentar formalmente su dimisión al presidente de la República, se le obligó a permanecer en el mismo y a aceptar la votación.

Si la consecuencia lógica de un voto de desconfianza, como la de una moción de censura, es el derribar al Gobierno, la dimisión anticipada del Gobierno Lerroux debería haber satisfecho los deseos de los proponentes de la desconfianza, los cuales verían así su intento realizado sin necesidad de llegar a una votación de resultados siempre inciertos, aunque no tanto en este caso. Sin embargo, motivaciones políticas más profundas, en las que no es mi intención

${ }^{28} \mathrm{~N}$. Alcalá Zamora, op. cit., pág. 138.

${ }_{29}$ En el mismo sentido, se manifestó recientemente el profesor Villarroya (J. Tomás Villatroya, «EI voto de desconfianza en la II República», en Cuadernos de la Cátedra Fa. drique Furio Ceriol, 3, mayo 1981, págs. 1-10). 
entrar aquí, les llevaron a continuar el proceso iniciado hasta la votación misma de la proposición y, como resultado de la misma, a la pretensión de inhabilitación de los miembros del Gobierno derribado para formar parte de uno nuevo.

Un doble problema se encerraba, pues, en las consecuencias del voto de la proposición de desconfianza. En primer lugar, la procedencia de la realización de la votación misma, dado que el Gobierno presentó su dimisión en medio del debate; en segundo lugar, la procedencia de la pretensión de inhabilitar a los miembros del Gobierno derribado para poder formar parte de otro nuevo.

En cuanto al primer aspecto, parece de toda lógica que la dimisión del Gobierno, notificada al presidente de la Cámara - aunque no presentada en forma al presidente de la República, dado que se obligó a Lerroux a permanecer en el debate-, debió haber parado o al menos suspendido temporalmente el debate a la espera de que la dimisión fuese formalmente efectiva, pues difícilmente se le puede negar la confianza a un Gobierno que ya no existe. Como dijo gráficamente Lerroux entonces: «En este puesto ya no continúa nadie y en este lugar ya no creo que pueda hablar nadie» ${ }^{30}$. Obviamente, la dimisión no sería efectiva sino después de presentada y aceptada formalmente por el presidente de la República, pero en la práctica debería haber sido suficiente con la manifestación de la intención del Gobierno para suspender el debate. Ello, sin embargo, no fue interpretado así por el presidente de la Cámara, quien se limitó a darse por notificado de la intención del Gobierno y a pedirle a continuación que permaneciese en su puesto hasta el final del debate. Y esto lo hizo Besteiro muy posiblemente - aunque así no se mencionase y se aludiesen motivaciones de otro tipo ${ }^{31}$ - en aplicación extensiva del artículo 63 de la Constitución, que establecía en su último párrafo que el presidente del Consejo y los ministros «no podrán excusar su asistencia a la Cámara cuando sean por ella requeridos».

Pero el deseo de la minoría socialista de que se llevase a cabo la votación venía justificado por la inhabilitación de los miembros del Gobierno derribado para formar uno nuevo, que consideraban se debía derivar del resultado de la misma en aplicación del último párrafo del artículo 75 de la Constitución. $\mathrm{Y}$ este era el segundo aspecto del problema. Desde su punto de vista, el triunfo de su proposición de desconfianza suponía la necesidad de la aplicación inmediata del precepto contenido en el artículo citado, por el cual el presidente de la República debía «separar» necesariamente al presidente del Gobierno y a sus ministros en el caso de que las Cortes les negasen de modo explícito su confianza.

Pero, suponiendo que fuese legítimo derivar del último párrafo del ar-

${ }^{30}$ DSCC, 405, 3 de octubre de 1933, pág. 15432.

${ }^{31}$ Entonces dijo el presidente de la Cámara, Besteiro: «Yo digo al señor presidente del Consejo de Ministros que es muy peligroso abandonar el Parlamento y presentar la dimisión del Gobierno, dejando a los partidos políticos en un mar tumultuoso de pasiones. $\mathrm{La}$ discusión tendrá todos los riesgos que se quiera; pero por medio de ella y en virtud de la esencia del Parlamento, podemos llegar a hacer alguna luz en este caos en que, por faltas de unos y de otros, estamos sumidos. Su señoría ha dirigido aquí cargos a determinados diputados. Algunos han pedido la palabra. Yo ruego a su señoría que permanezca en el banco azul hasta que dichos diputados hablen respondiendo a esos cargos». (DSCC, 405,3 de octubre de 1933, pág. 15432). 
tículo 75 de la Constitución la existencia de un voto de desconfianza diferenciado y suponiendo que este voto no tuviese que ajustarse a los requisitos establecidos en el artículo 64, ¿era también legítima la pretensión de inhabilitar a los ministros del Gobierno derribado para formar parte del que habría de sucederle? La pretensión socialista, que analiza con detalle en este aspecto el profesor Royo Villarroya ${ }^{32}$, era bastante novedosa, no tenía precedente constitucional y los propios especialistas de la época no tuvieron una opinión uniforme al respecto. Para unos, los socialistas, que seguían el criterio profesional de De los Ríos y de Jiménez de Asúa ${ }^{33}$, la inhabilitación debería ser absoluta y afectar a todos los miembros del Gabinete, incluido, por supuesto, su presidente. Para otros, entre quienes se encontraba Pérez Serrano y un informe de los propios letrados de Cortes, la inhabilitación debería alcanzar fundamentalmente al presidente del Gobierno, pero no a los demás ministros, dado que aquél era el responsable de la política del Gobierno y no individualmente sus ministros ${ }^{34}$. Ello, a mi modo de ver, contradecía lo establecido en el artículo 91 de la Constitución, que declaraba a los miembros del Gobierno solidariamente responsables de su política. Sin embargo, fue el criterio seguido, y Lerroux no fue vuelto a llamar a formar Gobierno.

$\mathrm{La}$ inhabilitación de los miembros del Gabinete caído para formar un nuevo Gobierno, dirigida especialmente contra la figura de Lerroux, la considero un tanto exagerada y, desde luego, sin precedente en la época tanto en los textos como en las prácticas constitucionales españolas y de otros países. Por el contrario, sobre todo en países como Francia, muy habituada a las frecuentes crisis ministeriales, lo normal era que los nuevos gabinetes contasen con miembros de los anteriormente derribados e incluso que fuesen formados por un primer ministro miembro del Gobierno anterior. Por otra parte, aunque se citase el artículo 75 como la justificación legal de tal inhabilitación, no hay que olvidar que el mismo artículo establecía también la plena libertad del presidente de la República para nombrar y separar al presidente del Gobierno. Y si tenía la obligación de separarlo cuando las Cortes le negaren de modo explícito su confianza, una vez destituido tal Gobierno y, por tanto, inexistente ya como cuerpo colectivo no es demasiado desatinado el pensar que el presidente de la República podría encargar de nuevo al mismo primer ministro la formación de otro Gabinete, que sería ya una entidad totalmente distinta a la anterior, posiblemente con un programa diferente, etc.

Efectivamente, el artículo 75 daba al presidente de la República una enorme libertad de movimientos a este fin. De hecho, Alcalá-Zamora se movía en la resolución de las crisis ministeriales con entera libertad, y no sólo extendía sus consultas previas a la formación de nuevo Gabinete también a líderes políticos y a personalidades con mínima o ninguna representación o apoyo parlamentario, sino que con una enorme frecuencia ignoró totalmente el equilibrio de fuerzas existentes en la Cámara y designó para formar Gobierno a personas

${ }^{32} \mathrm{~J}$. Tomás Villarroya, op. cit., págs. 4 y sigs:

${ }^{33}$ Véase El Socialista, 5 de octubre de 1933; citado en J. Tomás Villarroya, op. cit., página 4.

${ }_{34}$ Cfr. Juan Simeón Vidarte, Las Cortes Constituyentes de 1931-1933, Grijalbo, Barcelona, 1977, pág. 662 . 
que no reunían detrás de sí a la mayoría de la misma. Y ello tuvo una incidencia más grave en el conflictivo período que cubrieron las segundas Cortes de la República ${ }^{35}$.

Esta actitud del presidente de la República no fue demasiado bien acogida por los líderes de las fuerzas políticas más importantes del momento, quienes veían así ignorado su criterio o valorado en pie de igualdad con el de quienes apenas a nadie representaban. $Y$ sus protestas no fueron ignoradas por AlcaláZamora, quien años más tarde, en su análisis crítico de la Constitución republicana, se haría eco de ellas y defendería con vehemencia la prerrogativa presidencial que, en su criterio, le atribuía el artículo 75 de la Constitución de $1931^{36}$. Claro que esta prerrogativa no tenía por qué ser interpretada de una manera tan radical ni llevarle, como de hecho ocurrió, a ir contra la esencia parlamentaria del propio régimen, ignorando una de las prácticas tan propias del parlamentarismo como lo es el que la formación del Gobierno responda al sentir de la Cámara y sea una emanación de la mayoría de la misma.

No considero, pues, tampoco válida ni constitucionalmente fundamentada la consecuencia que la minoría socialista de las Cortes Constituyentes pretendió obtener de la aprobación de su voto de desconfianza. Y este fue el criterio seguido entonces por el propio presidente de la República, que, si bien no volvió a llamar a Lerroux a formar un nuevo Gobierno, tampoco aceptó la inhabilitación de los miembros de su Gabinete y terminó por designar nuevo primer ministro a Diego Martínez Barrio, miembro destacado del mismo. Y ello lo hizo el presidente -como confesaría más tarde en sus memoriasde una manera intencionada, para que quedase muy claro su rechazo de la vía utilizada por la minoría socialista y de la consecuencia que del voto de desconfianza se pretendía obtener ${ }^{37}$. Pero, además, y quizá como afrenta también a

${ }^{35}$ Véase, sobre este tema, el interesante trabajo del profesor J. Tomás Villarroya, «La formación de Gobierno durante la II República», en Revista de Estudios Políticos, 204, noviembre-diciembre 1975 , págs. 49-94.

${ }_{36}^{36}$ El artículo 75 de la Constitución republicana - llegaría a decir Alcalá Zamoradice que éstos (los ministros) se nombran, o separan a propuesta del presidente del Gobierno, y limita para éste sólo, eso sí, con toda clatidad y la compensación del contraste, la pretrogativa del presidente de la República para concederle o retirarle su confianza. Esa prerrogativa, contrapartida de otras limitaciones, contrapeso de otras potestades de la Cámara, es tan necesaria, que sin ella difícilmente podría el Jefe del Estado cumplir lealmente, con tranquilidad de conciencia, y esperanza de eficacia, la promesa que el artículo 72 le exige, de fidelidad a la República, de buscar el bien de ésta y de la nación». Pero, añadiría, «con olvido de cuanto significa el artículo 75 , y confirman las concordancias de éste, se ha ido, derechamente en el propósito y tortuosamente en los medios, a arrebatar esa prerrogativa al Jefe del Estado, llevándola a la Cámara, o a una parte de la Cámara, que es aún peor. Si perteneciese al Parlamento la facultad de designar el presidente del Consejo, y, como un autómata, sólo incumbiera al presidente de la República firmar el decreto valía más haber dicho que lo designarían las Cortes, o, en nombre de éstas, el presidente de las mismas, o, mejor, el oficial mayor del Congreso que lleva el registro de la composición numérica de los grupos, y que, a su vez, podría delegar en un ujier despierto, de los que presencian las votaciones, para que hiciese el recuento» (N. Alcalá Zamora, op. cit., págs. 140-141).

${ }_{37}$ Sobre la actitud de Alcalá Zamora en este problema, véase sus Memorias, en las que se refitió con duras palabras a todo lo sucedido, llegando a decir: «Al plantearse la crisis de octubre fue base de todos mis encargos que en el nuevo Gobierno entraran algunos ministros del dimisionario, para no asentir con una tácita coincidencia a la inconstitucional 
las pretensiones socialistas, Alcalá-Zamora no cumplió el mandato del artículo 75 , de separar al presidente y a los ministros censurados, sino que se limitó a aceptar su dimisión, y así constó en el Decreto presidencial de 8 de octubre de 1933, publicado en la Gaceta del día siguiente, que daba fin al problema.

\section{CONCLUSIONES}

Creo, en definitiva, que - prescindiendo de las motivaciones políticas subyacentes - en el fondo del problema que se planteó en los debates de los días 2 y 3 de octubre de 1933 y que precedieron a la disolución de las Cortes constituyentes, se encontraba una defectuosa redacción de la Constitución de 1931, que en ningún momento dejó claramente establecida la íntima relación existente entre la falta de confianza en el Gobierno, prevista en el artículo 75, y los mecanismos establecidos para manifestarla, previstos en el artículo 64 .

La simple alusión al voto de desconfianza, como forma «indirecta» de censura, en el último apartado del artículo 64 - como ya constaba en el anteproyecto de la Comisión Jurídica Asesora (art. 50) - hubiera evitado el planteamiento de este problema, que tanta transcendencia llegó a tener en su momento.

Y ello por no exigir una mayor especificidad en la regulación general de las : relaciones Gobierno-Cortes, que obligaría a incluir figuras constitucionales que hoy son más frecuentes, como el voto de investidura (art. 99 de la Constitución éspañola de 1978; art. 63 de la Ley Fundamental de Bonn de 1949), o la propia cuestión de confianza (art. 112 de la Constitución española; art. 68 de la Ley Fundamental de Bonn; art. 49 de la Constitución francesa de 1958; artículo 84 de la Constitución griega de 1975; art. 196 de la Constitución portuguesa de 1976), que suponen una profundización en la racionalización del parlamentarismo, pero que era bastante difícil que llegase a establecer el constitucionalismo de la época, que ya había dado un gran paso adelante con la regulación formal de la moción de censura. Por lo demás, no deja de ser paradójico que - a pesar de su utilidad - el nuevo constitucionalismo, posterior a la Segunda Guerra Mundial, haya seguido en esta línea de profundización en las técnicas de racionalización del parlamentarismo con la idea exclusiva de asegurar un Ejecutivo estable y, con ello, un régimen democrático también estable. $\mathrm{Y}$ es paradójico porque la experiencia histórica ha demostrado sobremanera que tales técnicas constitucionales son absolutamente insuficientes, o ineficaces, a tal fin, y que la estabilidad gubernamental y de los propios sistemas políticos depende fundamentalmente de otros factores, tales como la consolidación de un potente sistema de partidos, el desarrollo de un amplio

enormidad ideada por. Prieto y algunos otros ofuscados. En cambio me pareció que Lerroux, aunque tampoco quedaba inhabilitado, no debía ser el presidente, pues ya que era imposible conservar las Constituyentes, que habían apresurado su muerte suicidándose, quería al menos buscar otro presidente que no simbolizara la reciente lucha y sí una esperanza de conciliación republicana» (N. Alcalá Zamora, Memorias, Planeta, Batcelona, 1977, páginas 244-246). 
consensus social, etc. ${ }^{38}$. El propio Mirkine-Guetzévitch, divulgador de la idea del «parlamentarismo racionalizado», haciendo años más tarde un balance de lo tristemente ocurrido en la mayoría de los países que entre 1919 y 1939 introdujeron esta forma de relación entre el Gobierno y el Parlamento, como manera de asegurar, no sólo la estabilidad gubernamental, sino la del propio sistema democrático, como consecuencia, llegaría a decir: «Des partis puissants et disciplinés, voila le vrai régime parlamentaire» ${ }^{39}$.

${ }^{38}$ Véase, en este sentido, A. Bar, «El sistema de partidos en España: ensayo de caracterización», trabajo en prensa; M. Ramírez, «Aproximación al sistema de partidos en España (1931-1981)», en Estudios sobre Historia de España. Homenaje a Manuel Tuñón de Lara, Universidad Internacional Menéndez Pelayo, Madrid, 1981, págs. 211-225.

${ }^{39} \mathrm{~B}$. Mirkine-Guetzévitch, «L'echec du parlamentarisme 'rationalisé'», en Revue Internationale d'Histoire Politique et Constitutionnelle, 14, abril-junio 1954, págs. 99-118. 